\title{
Cardiac overexpression of catalase rescues cardiac contractile dysfunction induced by insulin resistance: role of oxidative stress, protein carbonyl formation and insulin sensitivity
}

Received: 21 December 2005 / Accepted: 10 February 2006 / Published online: 4 April 2006

C) Springer-Verlag 2006

\begin{abstract}
Aims/hypothesis: Insulin resistance leads to oxidative stress and cardiac dysfunction. This study examined the impact of catalase on insulin-resistanceinduced cardiac dysfunction, oxidative damage and insulin sensitivity. Methods: Insulin resistance was initiated in FVB and catalase-transgenic mice by 12 weeks of sucrose feeding. Contractile and intracellular $\mathrm{Ca}^{2+}$ properties were evaluated in cardiomyocytes including peak shortening (PS), time-to-PS (TPS), time-to-90\% relengthening $\left(\mathrm{TR}_{90}\right)$, half-width duration (HWD), maximal velocity of shortening/relengthening $( \pm \mathrm{dL} / \mathrm{dt})$, fura-fluorescence intensity change $(\Delta \mathrm{FFI})$ and intracellular $\mathrm{Ca}^{2+}$ clearance rate $(\tau)$. Reactive oxygen species (ROS) and protein damage were evaluated with dichlorodihydrofluorescein and protein carbonyl formation. Results: Sucrose-fed mice displayed hyperinsulinaemia, impaired glucose tolerance and normal body weight. Myocytes from FVB sucrose-fed mice exhibited depressed PS and $\pm \mathrm{dL} / \mathrm{dt}$, prolonged $\mathrm{TR}_{90}$ and $\tau$, and reduced $\Delta$ FFI associated with normal TPS and HWD compared with those from starch-fed control mice. ROS and protein carbonyl formation were elevated in FVB sucrose-fed mice. Insulin sensitivity was reduced, evidenced by impaired insulin-stimulated 2-deoxy-D- $\left[{ }^{3} \mathrm{H}\right]$ glucose uptake. Western blot analysis indicated that sucrose feeding: (1) inhibited insulin-stimulated phosphorylation of insulin receptor and Akt; (2) enhanced proteintyrosine phosphatase 1B (PTP1B) expression; and (3) suppressed endothelial nitric oxide synthase (eNOS) and $\mathrm{Na}^{+}-\mathrm{Ca}^{2+}$ exchanger expression without affecting peroxisome proliferator-activated receptor $\gamma(\operatorname{PPAR} \gamma)$, sarco(endo)plasmic reticulum $\mathrm{Ca}^{2+}$-ATPase isozyme $2 \mathrm{a}$ and phospholamban. Catalase ablated insulin-resistance-
\end{abstract}

F. Dong $\cdot$ C. X. Fang $\cdot$ X. Yang $\cdot$ X. Zhang $\cdot$

F. L. Lopez $\cdot$ J. Ren $(\bowtie)$

Division of Pharmaceutical Sciences and Center

for Cardiovascular Research and Alternative Medicine,

University of Wyoming,

1000 E. University Avenue, Department 3375,

Laramie, WY 82071, USA

e-mail: jren@uwyo.edu

Tel.: +1-307-7666131

Fax: +1-307-7662953 induced mechanical dysfunction, ROS production and protein damage, and reduced eNOS, but not insulin insensitivity. Catalase itself decreased resting FFI and enhanced expression of PTP1B and PPAR $\gamma$. Conclusions/ interpretation: These data indicate that catalase rescues insulin-resistance-induced cardiac dysfunction related to ROS production and protein oxidation but probably does not improve insulin sensitivity.

Keywords Catalase - Insulin - Insulin resistance · Myocyte $\cdot$ Shortening $\cdot$ Protein carbonyl

Abbreviations $-\mathrm{dL} / \mathrm{dt}$ : maximal velocity of relengthening $\cdot+\mathrm{dL} / \mathrm{dt}$ : maximal velocity of shortening eNOS: endothelial nitric oxide synthase $\cdot$ HWD: half-width duration - NCX: $\mathrm{Na}^{+}-\mathrm{Ca}^{2+}$ exchanger $\cdot$ pAkt: phosphorylated Akt - PLB: phospholamban - PPAR $\gamma$ : peroxisome proliferator-activated receptor $\gamma \cdot$ PS: peak shortening - PTP1B: protein-tyrosine phosphatase 1B . ROS: reactive oxygen species - SERCA2a: sarco(endo) plasmic reticulum $\mathrm{Ca}^{2+}$-ATPase isozyme $2 \mathrm{a} \cdot \mathrm{TPS}$ : time-topeak shortening $\cdot \mathrm{TR}_{90}$ : time-to- $90 \%$ relengthening $\cdot \Delta \mathrm{FFI}$ : fura-fluorescence intensity change $\cdot \tau$ : (tau) intracellular $\mathrm{Ca}^{2+}$ clearance rate

\section{Introduction}

Metabolic syndrome characterised by obesity, hypertension and insulin resistance is a serious medical problem resulting from interactions between genetic makeup and lifestyle [1-3]. Individuals with insulin resistance exhibit a high incidence of cardiovascular diseases such as ventricular dysfunction [1-3]. Compromised heart function associated with insulin resistance is characterised by impaired cardiac efficiency, reduced ventricular function and coronary heart disease [2-7]. Many of these dysfunctions are reminiscent of those found in diabetic individuals with compromised heart function. It has been demonstrated that diabetic heart dysfunction is often characterised by prolonged action-potential duration, impaired ventricular 
compliance, reduced cytosolic $\mathrm{Ca}^{2+}$ clearance and prolonged ventricular relaxation [8-10]. However, it has not been fully elucidated whether prediabetic insulin resistance directly predisposes hearts to these diabetic mechanical defects.

Binding of insulin to its receptor initiates tyrosine autophosphorylation of insulin receptor [11]. The metabolic effects of insulin are mediated through IRS-1/IRS-2mediated activation of the phosphatidylinositol-3 kinase pathway [12]. Several post-insulin-receptor molecules have been indicated to play significant roles in insulin signalling, including the serine/threonine protein kinase Akt, protein-tyrosine phosphatase 1B (PTP1B), peroxisome proliferator-activated receptor $\gamma(\operatorname{PPAR} \gamma)$, and mammalian target of rapamycin and S6 kinase [13-15]. It has been speculated that malfunction of these signalling molecules (either dampened or hyperactivated) may contribute to development of insulin resistance $[3,16]$. Therefore, this study aimed to investigate the impact of antioxidant catalase on prediabetic insulin-resistance-induced cardiac mechanical dysfunction, oxidative stress, protein damage and insulin sensitivity at the levels of glucose uptake, insulin-receptor tyrosine phosphorylation, Akt, PTP1B and PPAR $\gamma$. We also evaluated the level of endothelial nitric oxide synthase (eNOS), a down-stream target for Akt. Ample evidence has related accumulation of reactive oxygen species (ROS) to complications of diabetes and obesity $[17,18]$. However, the role of oxidative stress in cardiac dysfunction under insulin resistance is essentially unknown. We used a sucrose-diet-induced insulinresistance model with hyperinsulinaemia and hypertriglyceridaemia $[5,6,19]$. It is believed that changes in fatty acid composition and membrane fluidity may contribute to the elevated cholesterol content and cholesterol:phospholipid ratio [19]. Cardiac contractile properties, ROS, protein carbonyl formation, cardiac $\mathrm{Ca}^{2+}$-regulatory proteins including sarco(endo)plasmic reticulum $\mathrm{Ca}^{2+}$-ATPase isozyme 2a (SERCA2a), phospholamban (PLB) and $\mathrm{Na}^{+}-$ $\mathrm{Ca}^{2+}$ exchanger (NCX), as well as insulin-signalling molecules at both receptor and post-receptor levels, were examined in cardiomyocytes or myocardium from both sucrose-fed prediabetic insulin-resistant and starch-fed control mice.

\section{Materials and methods}

Experimental animals and induction of whole-body insulin resistance

The experimental procedure was approved by our Institutional Animal Care Committee. Four-month-old male FVB and catalase-transgenic mice $(\sim 18 \mathrm{~g})$ were fed either a cornstarch or sucrose (each providing $68 \%$ of total energy) diet (Research Diets, New Brunswick, NJ, USA) for 12 weeks. Generation and identification of cardiac-specific catalase-transgenic mice were described previously [20, 21]. A primer pair derived from the myosin heavy chain promoter and rat catalase cDNA was used with the reverse sequence of aat atc gtg ggt gac ctc aa and the forward sequence of cag atg aag cag tgg aag ga. A line with cardiac catalase activity of $1,456 \mu \mathrm{mol} \mathrm{min}-1 \mathrm{mg}^{-1}$ protein or $60-$ fold of that of the wild-type mouse was used in this study. Mice were maintained with a 12-h light/12-h darkness cycle with free access to tap water.

Intraperitoneal glucose tolerance test, glucose and insulin levels

Two days prior to killing, mice were fasted for $12 \mathrm{~h}$ and then given an i.p. injection of glucose ( $2 \mathrm{~g} / \mathrm{kg}$ body weight). Blood samples were drawn from the tail vein $15 \mathrm{~min}$ and immediately before the glucose challenge, as well as 15, 60 and $120 \mathrm{~min}$ thereafter. Blood glucose and insulin levels were determined using a glucose analyser and a mouse insulin ELISA kit (Linco Research, Inc., St Charles, MO, USA), respectively [19].

\section{Isolation of mouse ventricular myocytes}

Hearts were rapidly removed and perfused (at $37^{\circ} \mathrm{C}$ ) with Krebs-Henseleit bicarbonate buffer. After perfusion, ventricles were digested with $0.9 \mathrm{mg} / \mathrm{ml}$ collagenase D (Boehringer Mannheim Biochemicals, Indianapolis, IN, USA) for $10 \mathrm{~min}$ before being minced and washed to remove remnant enzyme. Extracellular $\mathrm{Ca}^{2+}$ was added incrementally back to $1.25 \mathrm{mmol} / \mathrm{l}$. Fresh myocytes were used within $8 \mathrm{~h}$. Cell viability was approximately $70 \%$ in all animal groups. Only rod-shaped myocytes with clear edges were selected for recording of mechanical properties [21].

\section{Cell shortening/relengthening measurements}

Mechanical properties of cardiomyocytes were assessed using a SoftEdge MyoCam system (IonOptix Corporation, Milton, MA, USA) [21]. Cell shortening and relengthening were assessed using the following indices: peak shortening (PS), time-to-PS (TPS) and time-to- $90 \%$ relengthening $\left(\mathrm{TR}_{90}\right)$, half-width duration (HWD), which reflects the duration from $50 \%$ shortening to $50 \%$ relengthening, and maximal velocities of shortening $(+\mathrm{dL} / \mathrm{dt})$ and relengthening $(-\mathrm{dL} / \mathrm{dt})$. In the case of altering stimulus frequency, the steady-state contraction was achieved (usually after the first five or six beats) before PS was recorded.

\section{Intracellular $\mathrm{Ca}^{2+}$ transient measurement}

A separate cohort of myocytes was loaded with fura-2/AM $(0.5 \mu \mathrm{mol} / 1)$ for $10 \mathrm{~min}$ and fluorescence measurements were recorded with a fluorescence photomultiplier system (IonOptix). Electrically paced $(0.5 \mathrm{~Hz})$ cells were exposed to light emitted by a $75 \mathrm{~W}$ lamp and passed through either a 360 or a $380 \mathrm{~nm}$ filter. Fluorescence emissions were 
Table 1 General features of starch- and sucrose-fed FVB and catalase (CAT)-transgenic mice

\begin{tabular}{lllllllll}
\hline Mouse group & $\begin{array}{l}\text { Body weight } \\
(\mathrm{g})\end{array}$ & $\begin{array}{l}\text { Heart } \\
\text { weight } \\
(\mathrm{mg})\end{array}$ & $\begin{array}{l}\text { Heart weight/ } \\
\text { body weight } \\
(\mathrm{mg} / \mathrm{g})\end{array}$ & $\begin{array}{l}\text { Liver } \\
\text { weight }(\mathrm{g})\end{array}$ & $\begin{array}{l}\text { Liver weight/body } \\
\text { weight }(\mathrm{mg} / \mathrm{g})\end{array}$ & $\begin{array}{l}\text { Kidney } \\
\text { weight }(\mathrm{g})\end{array}$ & $\begin{array}{l}\text { Kidney weight/body } \\
\text { weight }(\mathrm{mg} / \mathrm{g})\end{array}$ & $\begin{array}{l}\text { Plasma insulin } \\
(\mathrm{pmol} / \mathrm{l})\end{array}$ \\
\hline FVB-starch & $25.6 \pm 0.4$ & $136 \pm 7$ & $5.3 \pm 0.2$ & $1.20 \pm 0.06$ & $46.4 \pm 1.9$ & $0.34 \pm 0.02$ & $13.0 \pm 0.6$ & $113.6 \pm 8.5$ \\
FVB-sucrose & $26.3 \pm 0.6$ & $137 \pm 6$ & $5.2 \pm 0.2$ & $1.21 \pm 0.05$ & $46.2 \pm 1.5$ & $0.35 \pm 0.01$ & $13.5 \pm 0.5$ & $244.7 \pm 14.0 *$ \\
CAT-starch & $25.6 \pm 0.5$ & $141 \pm 8$ & $5.5 \pm 0.3$ & $1.26 \pm 0.02$ & $49.1 \pm 0.7$ & $0.37 \pm 0.03$ & $14.3 \pm 0.9$ & $108.1 \pm 8.3$ \\
CAT-sucrose & $26.0 \pm 0.6$ & $143 \pm 11$ & $5.4 \pm 0.3$ & $1.27 \pm 0.07$ & $48.9 \pm 2.0$ & $0.36 \pm 0.03$ & $13.5 \pm 0.8$ & $240.0 \pm 24.3 *$ \\
\hline
\end{tabular}

Values are means \pm SEM, $n=14$ or 15 per group

${ }^{*} p<0.05$ vs corresponding starch group

detected between 480 and $520 \mathrm{~nm}$. Qualitative changes in intracellular $\mathrm{Ca}^{2+}$ concentration were inferred from the ratio of the fura-2 fluorescence intensity (FFI) at two wavelengths. Fluorescence decay time was also measured as an indication of the intracellular $\mathrm{Ca}^{2+}$ clearing rate [21].

\section{Protein carbonyl assay}

Protein carbonyl content of total protein lysate was determined as described [22]. In brief, protein was precipitated by adding an equal volume of $20 \%$ trichloroacetic acid (TCA) and centrifuged $(11,000 \times g)$ for $5 \mathrm{~min}$. The sample was resuspended in $10 \mathrm{mmol} / 1$ 2,4-dinitrophenylhydrazine solution for 15-30 $\mathrm{min}$ at room temperature before $20 \%$ TCA was added and samples were centrifuged $(11,000 \mathrm{~g})$ for $3 \mathrm{~min}$. The precipitate was resuspended in $6 \mathrm{~mol} / \mathrm{l}$ guanidine solution. The maximum absorbance $(360-390 \mathrm{~nm})$ was read against appropriate blanks $(2 \mathrm{~mol} / 1$ $\mathrm{HCl}$ ) and carbonyl content was calculated using the formula: absorption at $360 \mathrm{~nm} \times 45.45 \mathrm{nmol} /$ protein content (mg).

\section{Intracellular fluorescence measurement of ROS}

Intracellular oxidant stress was monitored by changes in fluorescence intensity resulting from intracellular probe oxidation. Cardiomyocytes were loaded with $10 \mu \mathrm{mol} / 1$ 5-(6)-chloromethyl-2', 7'-dichlorodihydrofluorescein diacetate (Molecular Probes, Eugene, OR, USA) for $30 \mathrm{~min}$ at $37^{\circ} \mathrm{C}$ before being washed with PBS buffer. Cells were sampled randomly using an Olympus BX-51 microscope equipped with an Olympus MagnaFire SP digital camera and ImagePro image analysis software (Media Cybernetics, Silver Spring, MD, USA). Fluorescence was calibrated with InSpeck microspheres (Molecular Probes). More than 150 cells per data point were evaluated using the gridcrossing method for cell selection in more than 20 visual fields [23].

\section{Glucose-uptake measurement}

Myocytes were cultured in a modified Dulbecco's modified Eagle's medium containing 5\% FBS, $5.0 \mathrm{mmol} / 1$ glucose and $1.0 \mathrm{mmol} / 1 \mathrm{CaCl}_{2}$ at $37^{\circ} \mathrm{C}$ for $30 \mathrm{~min}$. The cells were then washed three times with Krebs-Ringer-HEPES (KRH, $136 \mathrm{mmol} / \mathrm{l} \mathrm{NaCl}, 4.7 \mathrm{mmol} / \mathrm{l} \mathrm{KCl}, 1.25 \mathrm{mmol} / \mathrm{l}$ $\mathrm{CaCl}_{2}, 1.25 \mathrm{mmol} / 1 \mathrm{MgSO}_{4}, 10 \mathrm{mmol} / \mathrm{l} \mathrm{HEPES}, \mathrm{pH}$ 7.4) buffer and incubated with $2 \mathrm{ml} \mathrm{KRH}$ buffer at $37^{\circ} \mathrm{C}$ for $30 \mathrm{~min}$. Some cells were exposed to insulin $(100 \mathrm{nmol} / \mathrm{l}$, $10 \mathrm{~min}$ ). Glucose uptake was initiated by the addition of $0.1 \mathrm{ml} \mathrm{KRH}$ buffer and 2-deoxy-D- $\left[{ }^{3} \mathrm{H}\right]$ glucose $(0.2 \mu \mathrm{Ci} /$ $\mathrm{ml}$ ) and $5 \mathrm{mmol} / \mathrm{l}$ glucose. Glucose uptake was terminated 30 min later by washing the cells three times with cold PBS. The cells were lysed overnight with $0.5 \mathrm{ml} 0.5 \mathrm{~mol} / 1$
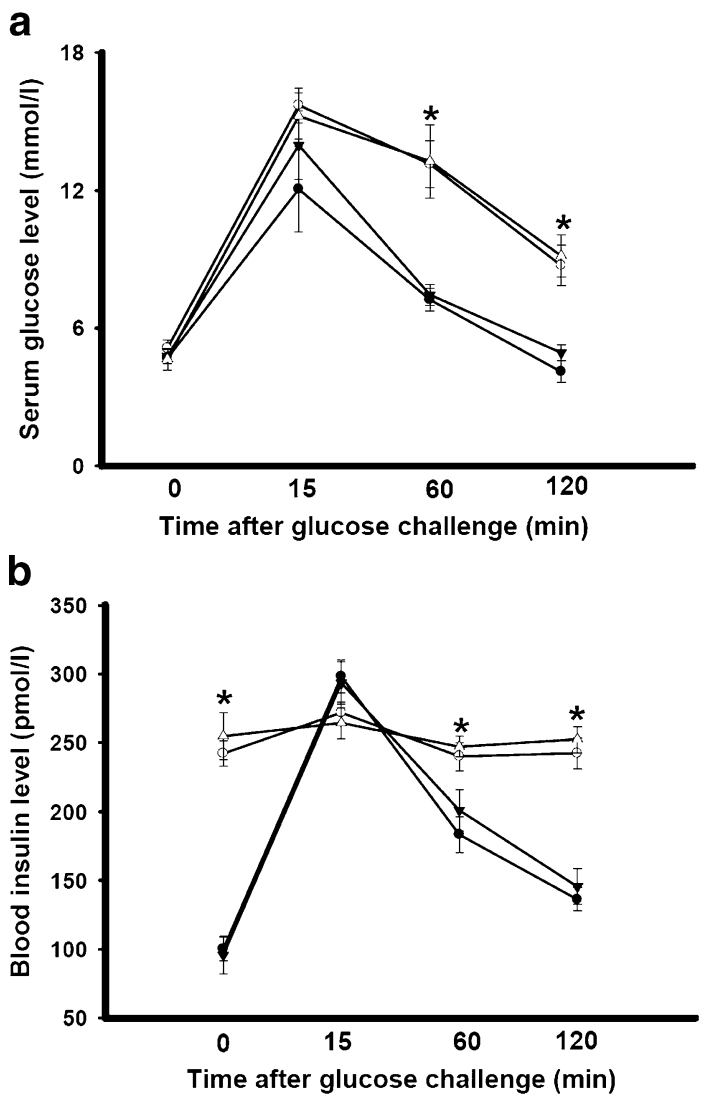

Fig. 1 Serum glucose (a) and blood insulin (b) levels in response to i.p. glucose challenge ( $2 \mathrm{~g}$ glucose $/ \mathrm{kg}$ body weight) in starch- and sucrose-fed FVB and catalase (CAT) mice. Filled circles, FVB starch-fed; open circles, FVB sucrose-fed; filled triangles, CAT starch-fed; open triangles, CAT sucrose-fed. The mice were fasted for $12 \mathrm{~h}$ before the tests. Means \pm SEM, $n=9$ or 10 mice per group, ${ }^{*} p<0.05$ between the starch- and sucrose-fed groups 


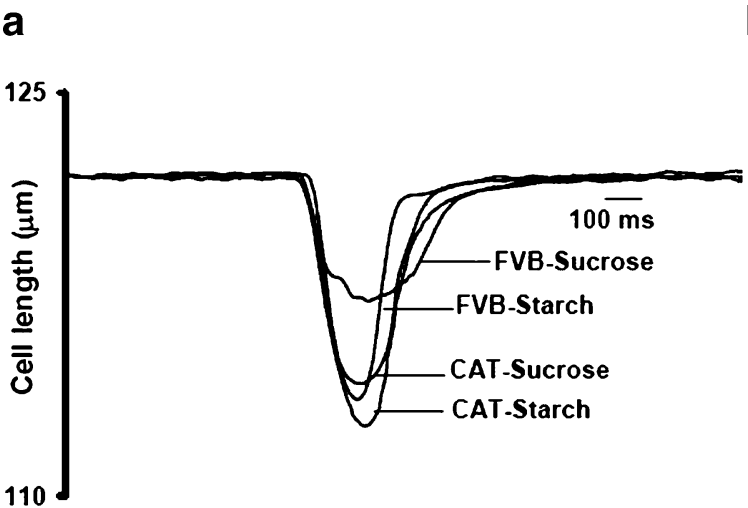

C

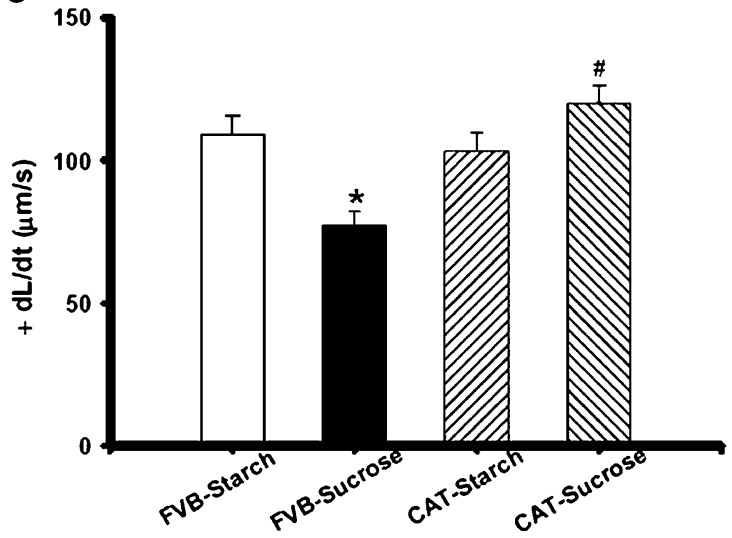

Fig. 2 Contractile properties of cardiomyocytes from starch- and sucrose-fed FVB and catalase (CAT) mouse hearts. a Representative traces depicting cell shortening in myocytes from each of the four groups; b resting cell length; $\mathbf{c}$ maximal velocity of shortening $(+d L / d t)$;

$\mathrm{NaOH}$ and $0.1 \%$ SDS (w/v). The radioactivity retained by the cell lysates was determined by a scintillation counter (LC 6000IC; Beckmann, Fullerton, CA, USA) and normalised to the protein amount measured with a Bradford Protein Assay Kit [24, 25]. To minimise the inter-assay variation, glucose uptake in all cell groups was normalised to the corresponding FVB-starch group.

Western blot analysis of Akt, phosphorylated Akt (pAkt), eNOS, tyrosine phosphorylation of insulin receptor, PPAR $\gamma$, PTP1B, SERCA2a, NCX and PLB

Tissue or cardiomyocyte samples were homogenised, sonicated and centrifuged $(12,000 \mathrm{~g})$. Protein $(50 \mu \mathrm{g} /$ lane) was separated on a Bio-Rad Minigel apparatus (MiniPROTEAN II; Bio-Rad, Hercules, CA, USA) before being transferred to nitrocellulose membranes. Membranes were incubated for $1 \mathrm{~h}$ in a blocking solution containing $5 \%$ milk in Tris-buffered saline (TBS), then were washed in TBS and incubated overnight at $4^{\circ} \mathrm{C}$ with anti-Akt $(1: 1,000)$,

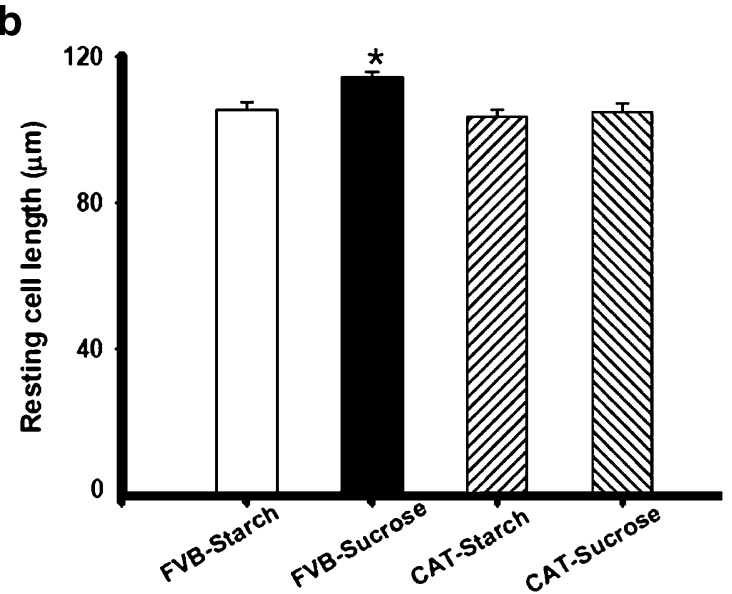

d

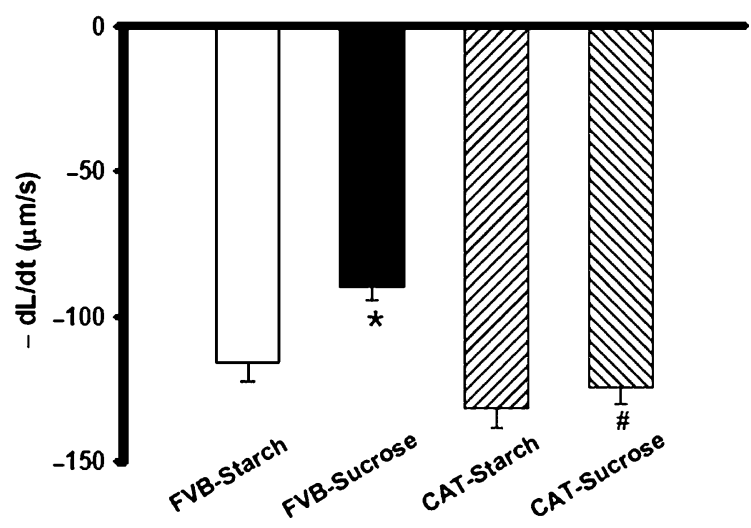

and d maximal velocity of relengthening $(-d L / d t)$. Means \pm SEM, $n=103-135$ cells/group, ${ }^{*} p<0.05$ vs FVB-starch group, $\# p<0.05$ vs FVB-sucrose group

anti-pAkt $(1: 1,000)$, anti-PTP1B $(1: 2,500)$, anti-SERCA2a $(1: 1,000)$, anti-NCX $(1: 1,000)$, anti-PLB $(1: 1,000)$, antityrosine phosphorylation of insulin receptor $(1: 1,000)$ and anti-PPAR $\gamma \quad(1: 1,000)$ antibodies. Anti-Akt, anti-pAkt (Ser473), anti-PPAR $\gamma$ and anti-tyrosine phosphorylation of insulin receptor (Tyr1146) antibodies were obtained from Cell Signaling (Beverly, MA, USA). PTP1B antibody was from BD Biosciences Pharmigen (San Diego, CA, USA), antibodies to SERCA2a (A7R5) and PLB (2D12) were kindly provided by S. Cala (Wayne State University, Detroit, MI, USA). Anti-NCX antibodies were obtained from Swant Company (Bellinzona, Switzerland). After removal of excess primary antibody binding, blots were incubated for $1 \mathrm{~h}$ with horseradish peroxidase-conjugated secondary antibody. Antibody binding was detected using enhanced chemiluminescence and films were evaluated with a Bio-Rad Calibrated Densitometer [21].

\section{Data analysis}

Data are expressed as means \pm SEM. Statistical comparisons were performed by ANOVA followed by a Newman-Keuls post hoc test. Significance was defined as $p<0.05$. 
a

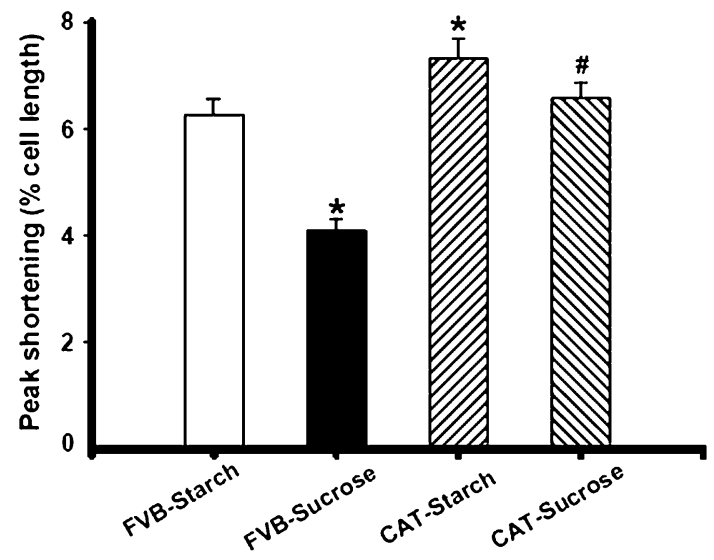

C

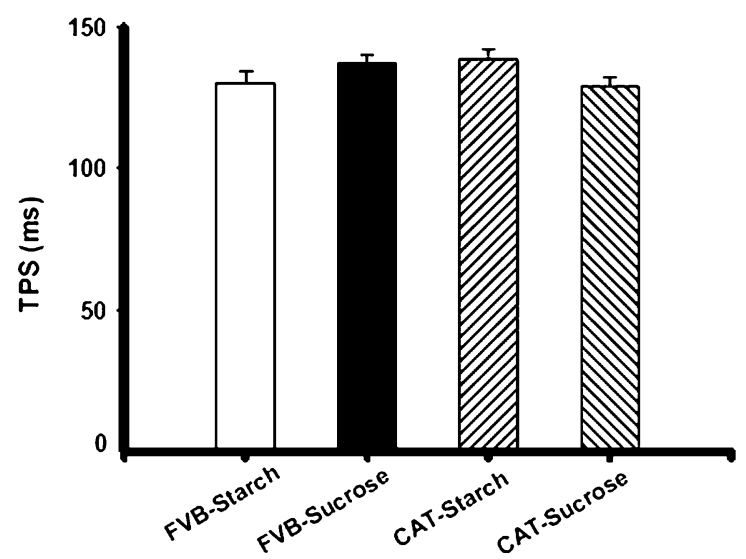

b

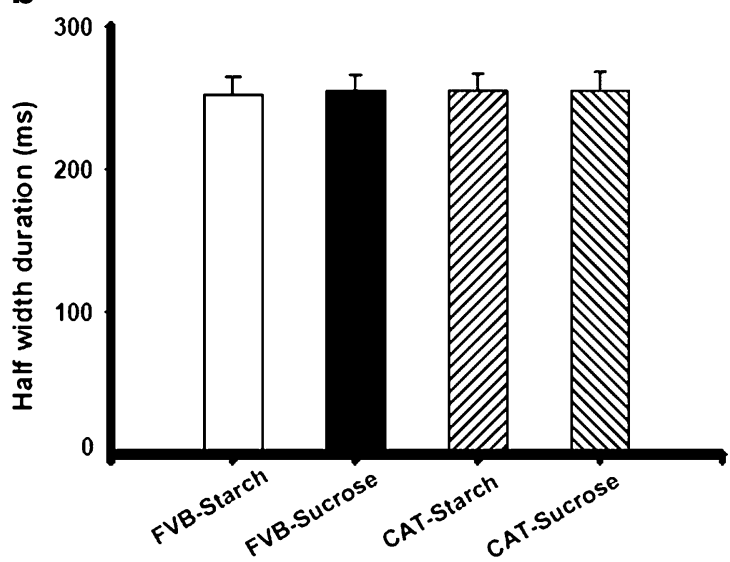

d

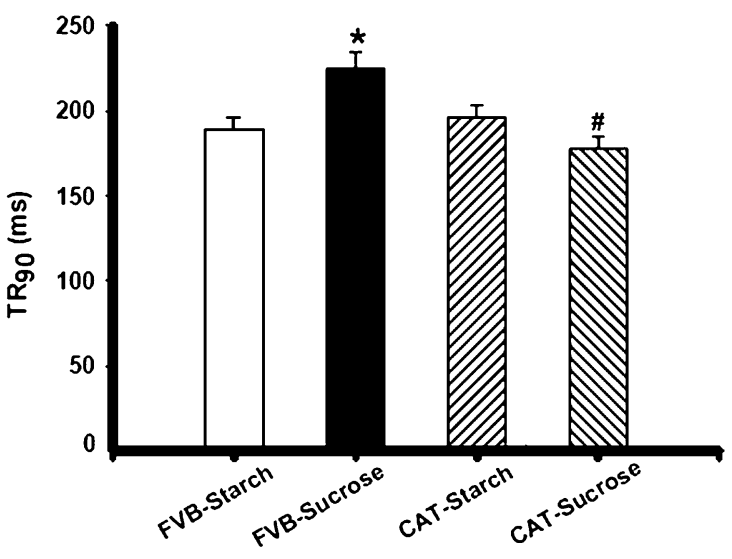

Fig. 3 Contractile properties of cardiomyocytes from starch- and sucrose-fed FVB and catalase $(C A T)$ mouse hearts. a Peak shortening (normalised to cell length); b half-width duration; $\mathbf{c}$ time-to-peak shortening (TPS); and d time-to-90\% relengthening (TR $\left.R_{90}\right)$. Means \pm SEM, $n=103-135$ cells/group, $*$ HDI60230 $<0.05$ vs FVB-starch group, $\# p<0.05$ vs FVB-sucrose group

\section{Results}

Experimental animals

No significant difference was found in body, heart, liver and kidney weight or organ/body weight ratio among all mouse groups. Consistent with the previous findings $[5,6$, 19], sucrose induced hyperinsulinaemia, which was not affected by the catalase transgene (Table 1). Following acute i.p. glucose challenge, blood glucose and insulin levels in starch-fed mice started to drop after peaking at $15 \mathrm{~min}$, and returned to nearly baseline values after $120 \mathrm{~min}$. However, the post-challenge glucose levels were maintained at high levels from 15 to $120 \mathrm{~min}$ in the sucrose-fed mice. Similarly, basal blood insulin levels were significantly higher in sucrose-fed FVB or catalase mice, and were barely responsive to acute i.p. glucose challenge (Fig. 1). The blood insulin levels were significantly higher in sucrose-fed mice than those of starch-fed mice at every time-point except $15 \mathrm{~min}$. These data revealed impaired glucose clearance and insulin insensitivity following sucrose feeding. There was no difference in basal fasting glucose levels among all mouse groups, excluding the presence of diabetes following sucrose dietary intake.
Mechanical and fluorescent properties of myocytes from starch- and sucrose-fed mice

The 12-week sucrose feeding regimen significantly enhanced the resting cell length of cardiac myocytes, which may be ablated by catalase transgene. Catalase itself did not affect the resting cell length (Fig. 2). As shown in Figs. 2 and 3, PS and $\pm \mathrm{dL} / \mathrm{dt}$ were significantly depressed in myocytes from the sucrose-fed FVB group compared with those from starch-fed FVB mice. Myocytes from sucrose-fed FVB mice displayed normal TPS and a significantly prolonged $\mathrm{TR}_{90}$ compared with those from the starch-fed FVB mice. The HWD, an index of the duration of late-contraction and early-relaxation, did not differ among all mouse groups. Interestingly, catalase effectively protected cardiomyocytes from sucrose-dietinduced mechanical dysfunctions. Our fura-2 study revealed depressed electrically stimulated $\Delta F F I$ and slowed intracellular $\mathrm{Ca}^{2+}$ clearing rate in myocytes from sucrose-fed FVB myocytes, a finding consistent with reduced PS and prolonged $\mathrm{TR}_{90}$ in these myocytes. Similarly to its effect on cell shortening, catalase abolished the sucrose-diet-induced decrease in $\triangle \mathrm{FFI}$ and prolongation in intracellular $\mathrm{Ca}^{2+}$ clearing. The resting intracellular 
a

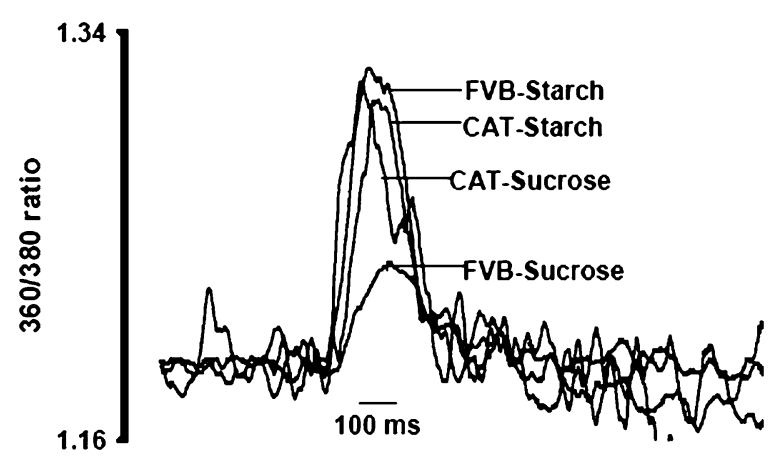

C

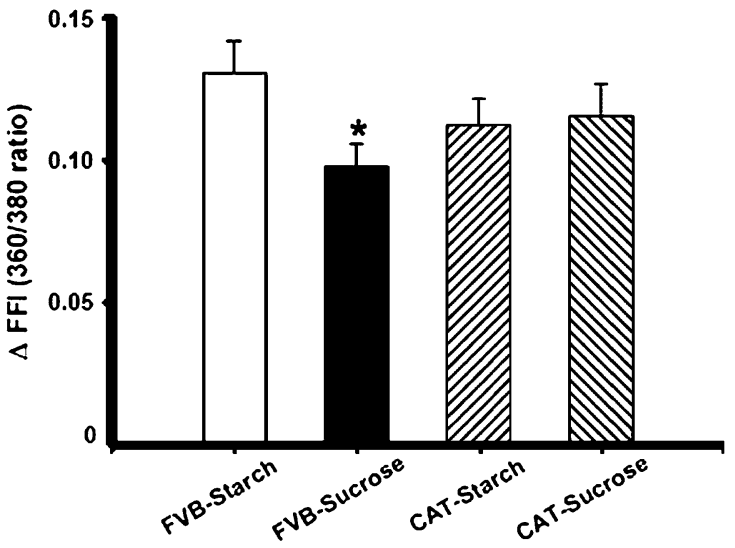

Fig. 4 Intracellular $\mathrm{Ca}^{2+}$ transient properties in cardiomyocytes from starch- and sucrose-fed FVB and catalase (CAT) mouse hearts. a Representative traces depicting intracellular $\mathrm{Ca}^{2+}$ transients in myocytes from each of the four groups; $\mathbf{b}$ resting intracellular $\mathrm{Ca}^{2+}$

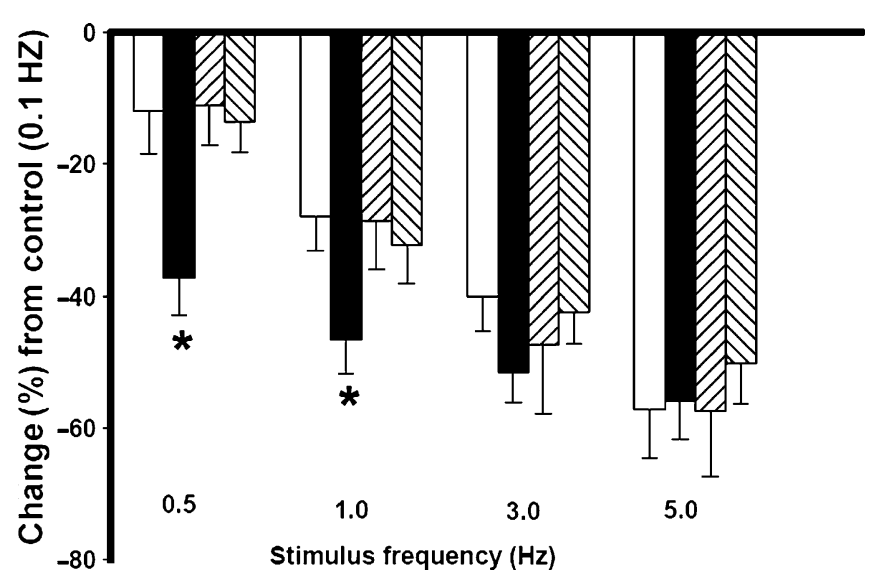

Fig. 5 Peak shortening amplitude of ventricular myocytes from starch- and sucrose-fed FVB and catalase $(C A T)$ mouse hearts at different stimulus frequencies $(0.1,0.5,1.0,3.0$ and $5.0 \mathrm{~Hz})$. PS at each stimulus frequency was normalised to that of $0.1 \mathrm{~Hz}$ of the same cell. Open bars, FVB starch fed; filled bars, FVB sucrose fed; hatched (rising left to right) bars, CAT starch-fed; hatched (rising right to left) bars, CAT sucrose fed. Means \pm SEM, $n=20$ cells per animal group. ${ }^{*} p<0.05$ vs starch-fed FVB group

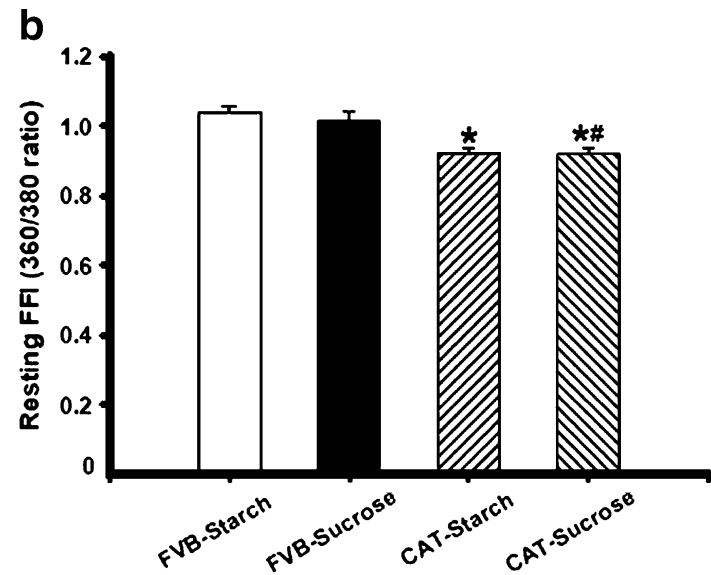

d

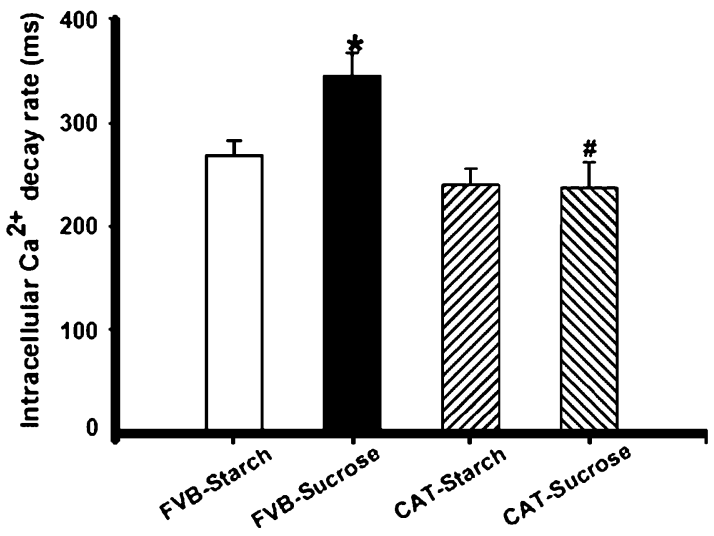

fura-2 fluorescence intensity $(F F I)$; c electrically stimulated increase in FFI $(\Delta F F)$; and $\mathbf{d}$ intracellular $\mathrm{Ca}^{2+}$ transient decay rate. Means \pm SEM, $n=31-43$ cells/group, ${ }^{*} p<0.05$ vs FVB-starch group, $\# p<0.05$ vs FVB-sucrose group

$\mathrm{Ca}^{2+}$ levels (resting FFI) were unaltered by sucrose diet although they were significantly reduced by catalase (Fig. 4).

Effect of increasing stimulation frequency on myocyte shortening

Rodent hearts normally contract at high frequencies, whereas our mechanical evaluation was conducted at $0.5 \mathrm{~Hz}$. To evaluate the impact of insulin resistance and catalase on cardiac contractile function under higher frequencies, we increased the stimulating frequency up to $5.0 \mathrm{~Hz}$ (300 beats $/ \mathrm{min})$. Cells were initially stimulated to contract at $0.5 \mathrm{~Hz}$ for $5 \mathrm{~min}$ to ensure a steady-state before commencing the frequency study. All recorded PSs were normalised to that obtained at $0.1 \mathrm{~Hz}$ in the same myocyte. Figure 5 shows a steeper inhibition in PS from sucrose-fed FVB mouse myocytes at 0.5 and $1.0 \mathrm{~Hz}$ of stimulating frequency compared with the starch-fed FVB group, suggesting that intracellular $\mathrm{Ca}^{2+}$ cycling function may be compromised under insulin resistance. However, the degree of PS reduction was similar between starch- and sucrose-fed groups at 3.0 and $5.0 \mathrm{~Hz}$, indicating normal 
a

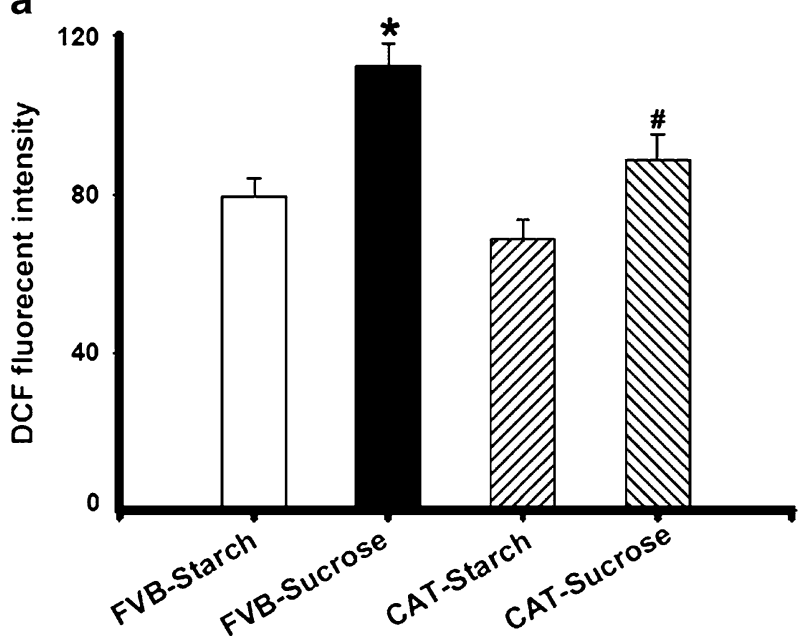

b

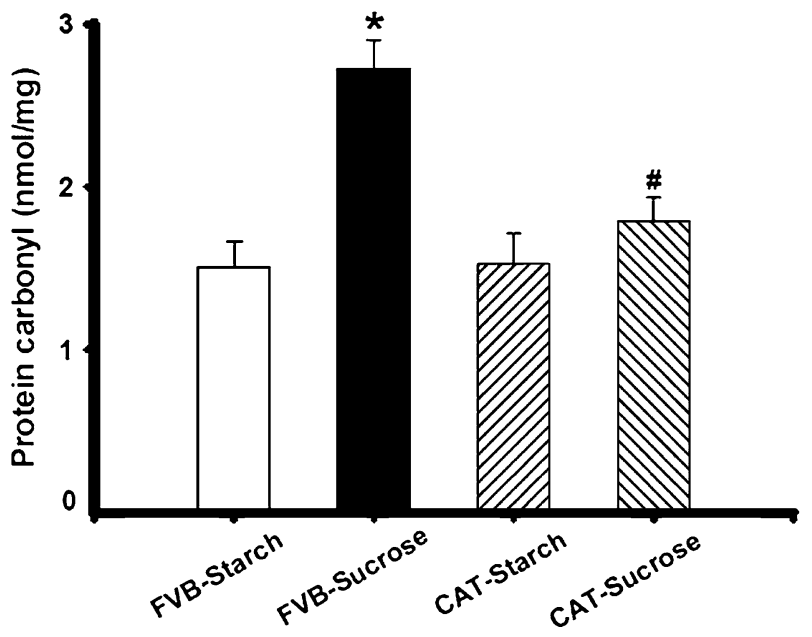

Fig. 6 Levels of cardiac ROS generation (a) and protein carbonyl formation (b) from FVB and catalase $(C A T)$ mice fed with either starch or sucrose diet for 12 weeks. Means \pm SEM, $n=20$ and 6 for ROS and protein carbonyl formation, respectively, ${ }^{*} p<0.05$ vs FVBstarch group, $\# p<0.05$ vs FVB-sucrose group. DCF 5-(6)-chloromethyl-2',7'-dichlorodihydrofluorescein diacetate

$\mathrm{Ca}^{2+}$ recycling capacity under insulin resistance at these frequencies. Interestingly, catalase nullified sucrose-dietinduced augmentation in inhibition of PS at 0.5 and $1.0 \mathrm{~Hz}$ while it elicited little effect on the stimulus frequency-PS relationship.

Effect of sucrose diet and catalase transgene on ROS and protein carbonyl formation

Results shown in Fig. 6 indicate that ROS generation and protein carbonyl formation, an indicator of protein oxidative damage, were significantly elevated in myocardium from sucrose-fed FVB mice. Although catalase itself had no effect on cardiac ROS generation and protein carbonyl formation, it significantly attenuated sucrose-diet-induced elevation in cardiac ROS generation and protein carbonyl formation, suggesting enhanced cardiac ROS accumulation and protein oxidative damage under insulin resistance and protection offered by the antioxidant catalase.

Effect of sucrose diet and catalase transgene on insulin-stimulated glucose uptake

To determine whether insulin sensitivity plays a role in sucrose-diet- and catalase-induced alteration of cardiomyocyte contractile function, basal and insulin-stimulated glucose uptake was determined. Basal glucose uptake was comparable in all groups. At $100 \mathrm{nmol} / \mathrm{l}$ insulin, starch-fed FVB mouse myocytes exhibited a significant increase in glucose uptake. However, the insulin-stimulated glucose uptake was blunted in myocytes from sucrose-fed FVB mice compared with the starch-fed FVB group. Catalase elicited little effect on insulin-stimulated glucose uptake in either starch- or sucrose-fed mouse myocytes. Insulinstimulated glucose uptake remained blunted in the sucrosefed catalase group (Fig. 7). These data suggest that catalase transgene does not affect insulin-stimulated glucose uptake in either starch- or sucrose-fed mouse cardiomyocytes.

Changes of protein expression in SERCA2a, PLB and NCX

To examine the possible mechanism behind insulin-resistance-induced cardiomyocyte contractile dysfunction and catalase-elicited protection, we evaluated cardiac expression of several key cardiac $\mathrm{Ca}^{2+}$-regulating proteins including SERCA2a, PLB and NCX. Our results revealed that sucrose diet did not significantly affect expression of SERCA2a and PLB, although it downregulated NCX

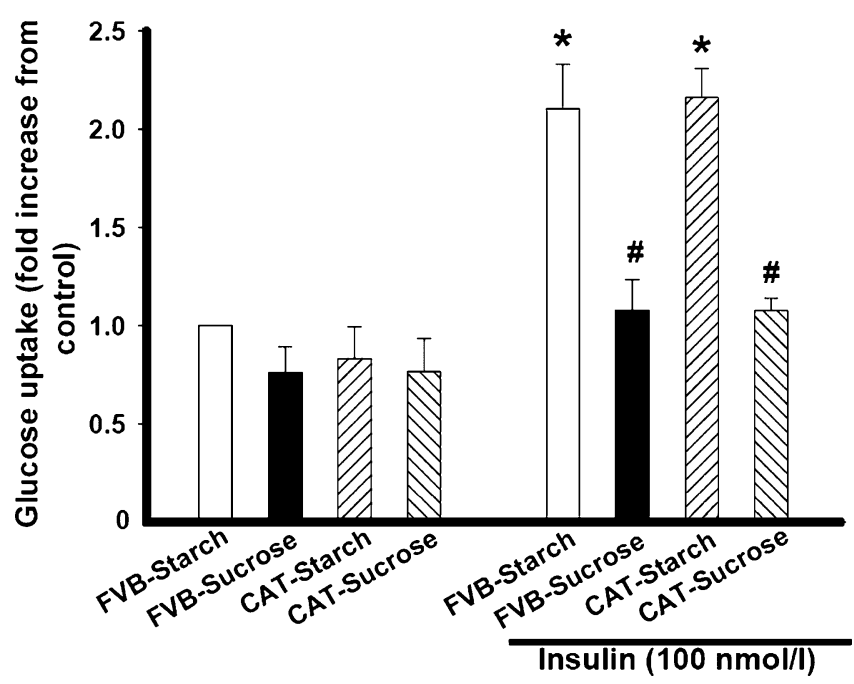

Fig. 7 Basal and insulin (100 nmol/1)-stimulated 2-deoxy-D- $\left[{ }^{3} \mathrm{H}\right]$ glucose uptake in myocytes from starch- and sucrose-fed FVB and catalase $(C A T)$ mouse hearts. All measurements are shown as fold increase of the respective control (FVB-Starch) value from the same assay. Means \pm SEM, $n=3$ or 4 preparations per group, ${ }^{*} p<0.05$ vs the respective group without insulin challenge, $\# p<0.05$ vs corresponding starch diet group 
a
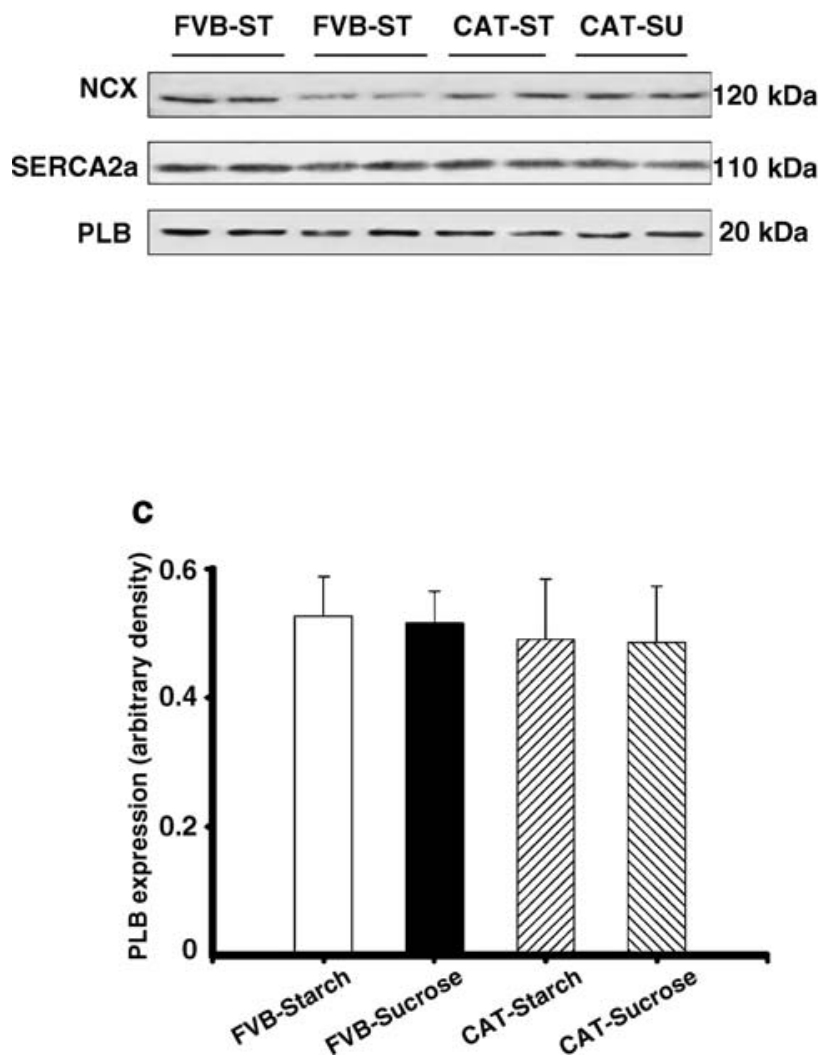

b

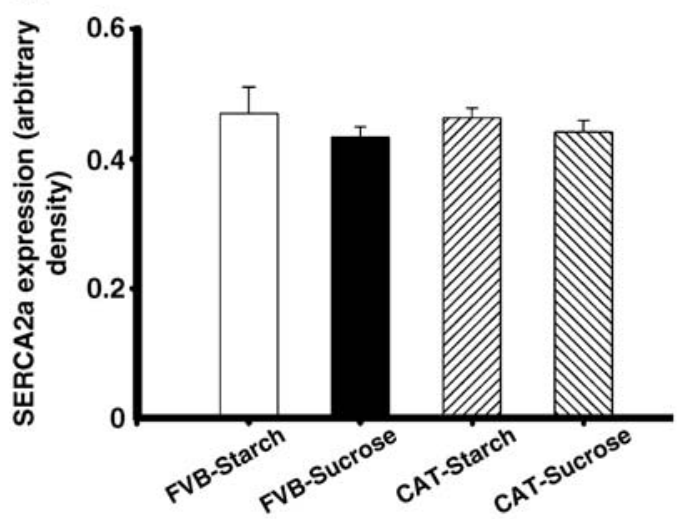

d

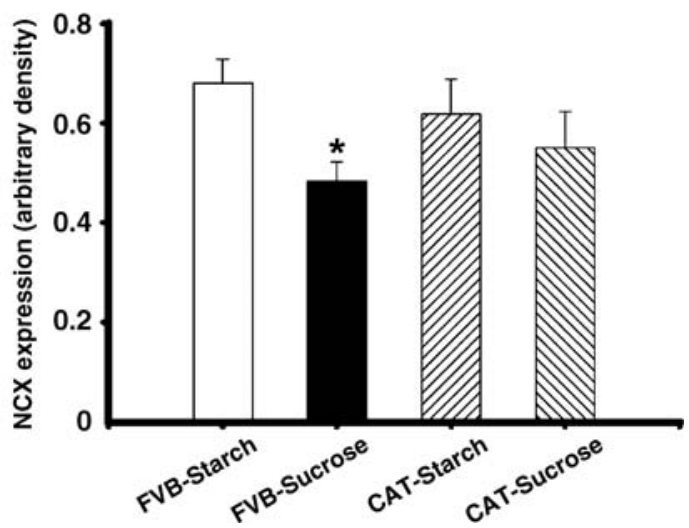

Fig. 8 Western blot analysis showing SERCA2a, PLB and NCX expression in starch- $(S T)$ and sucrose (SU)-fed FVB and catalase (CAT) mouse hearts. a Representative immunoblots depicting SERCA2a, PLB and NCX expression using anti-SERCA2a, anti-PLB and anti-NCX antibodies; b SERCA2a expression; c PLB expression; and d NCX expression. Means \pm SEM, $n=4,{ }^{*} p<0.05$ vs FVB-starch group

expression. Interestingly, sucrose-diet-induced downregulation of NCX was absent in catalase-transgenic mice (Fig. 8), suggesting a role of NCX in sucrose-diet-induced mechanical dysfunction and in the cardiac protective effect elicited by catalase.

Changes of protein expression in Akt, pAkt, tyrosine phosphorylation of insulin receptor, PPAR $\gamma$ PTP1B and eNOS

Insulin resistance is associated with interrupted insulin signalling at receptor and post-receptor levels $[1,3]$. To explore the contribution of insulin-signalling molecules to catalase-afforded cardiac protection against insulin-resistance-elicited mechanical dysfunction, we evaluated cardiac expression of Akt, pAkt, tyrosine phosphorylation (site Tyr1146) of the insulin receptor, PPAR $\gamma$, PTP1B and eNOS. Our results showed that sucrose-feeding-induced insulin resistance did not affect expression of total Akt with or without insulin stimulation. However, sucrose diet significantly enhanced basal Akt phosphorylation and blunted insulin-stimulated Akt phosphorylation. Catalase did not affect sucrose-diet- or insulin-stimulation-induced effects on Akt and pAkt (Fig. 9). Our further study revealed that insulin resistance significantly enhanced expression of PTP1B without affecting that of PPAR $\gamma$ and basal tyrosine phosphorylation of insulin receptor. The insulin-resistanceinduced rise in PTP1B level was further augmented by the catalase transgene. Catalase also upregulated expression of PTP1B and PPAR $\gamma$ but not insulin-receptor tyrosine phosphorylation (basal or insulin-stimulated). Consistent with its effect on Akt phosphorylation shown in Fig. 9, insulin-stimulated phosphorylation of insulin receptor was significantly inhibited by sucrose feeding. Catalase itself did not affect insulin-stimulated insulin-receptor phosphorylation. These data did not favour a likely contribution of insulin-receptor signalling to catalase-elicited cardiac protection against insulin resistance. Interestingly, insulin resistance induced a significant decrease in eNOS expression, which was blunted by catalase transgene (Fig. 10).

\section{Discussion}

Our results revealed that prediabetic insulin resistance elicits hyperinsulinaemia, glucose intolerance, impaired insulin-stimulated glucose uptake, cardiomyocyte contrac- 
a
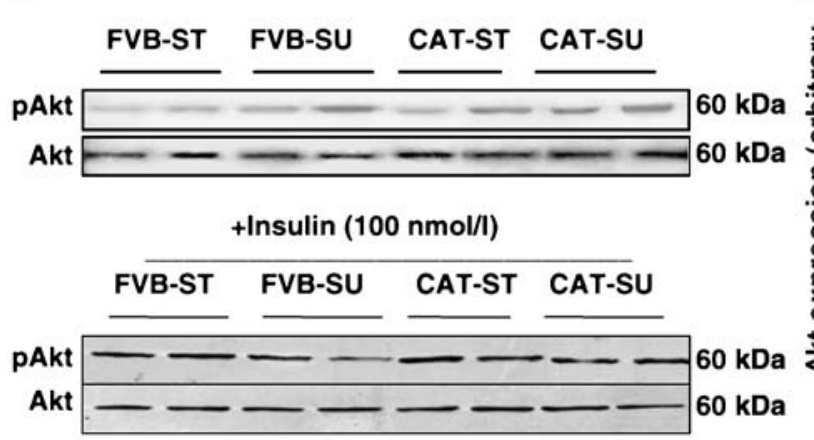

C

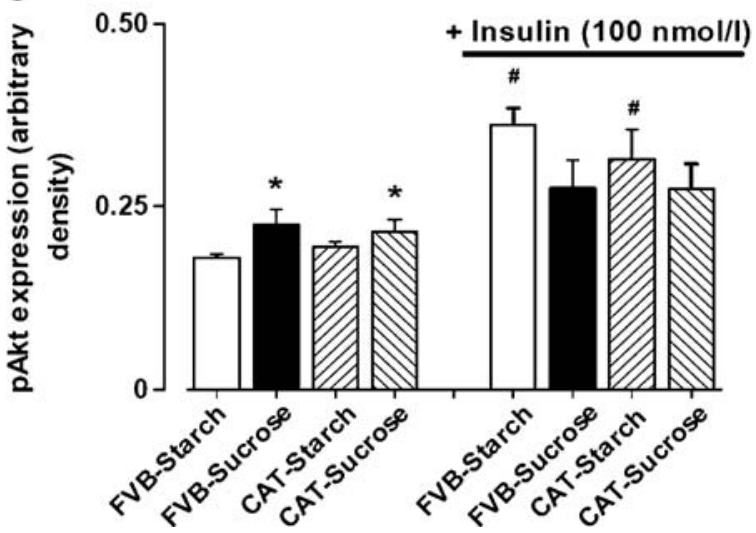

Fig. 9 Western blot analysis showing total and phosphorylated Akt level in starch- $(S T)$ and sucrose $(S U)$-fed FVB and catalase (CAT) mouse cardiomyocytes challenged with or without insulin (100 nmol/l for $10 \mathrm{~min}$ ). a Representative immunoblots depicting total and phosphorylated Akt using anti-Akt and anti-phospho-Akt

tile dysfunction, impaired intracellular $\mathrm{Ca}^{2+}$ handling and enhanced ROS generation and protein damage, as well as reduced NCX expression. With the exception of hyperinsulinaemia, glucose intolerance and impaired insulinstimulated glucose uptake, all of the above were alleviated by catalase. The 'sucrose diet' insulin-resistance-induced cardiac contractile and intracellular $\mathrm{Ca}^{2+}$ dysfunctions were associated with enhanced basal Akt phosphorylation and PTP1B expression, blunted insulin stimulation in phosphorylation of Akt and insulin receptor (Tyr1146) and reduced expression of eNOS but not that of PPAR $\gamma$ or basal insulin-receptor tyrosine phosphorylation, which suggests a relationship between altered insulin signalling and cardiac mechanical dysfunction. However, unlike its beneficial effect on insulin-resistance-induced mechanical and intracellular $\mathrm{Ca}^{2+}$ dysfunction, catalase failed to alleviate the insulin-resistance-induced deficiency in insulin sensitivity and post-receptor signalling. Only reduced expression of eNOS in response to insulin resistance, which may or may not be directly associated with the insulin-signalling pathway, was alleviated by catalase. Given the fact that whole-body insulin resistance, hyperinsulinaemia, impaired glucose uptake and glucose intolerance were unaffected by catalase, our data indicated that b

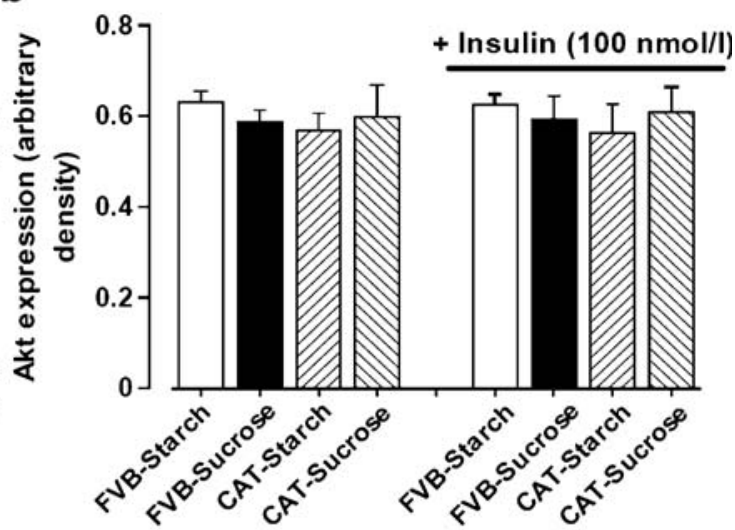

d

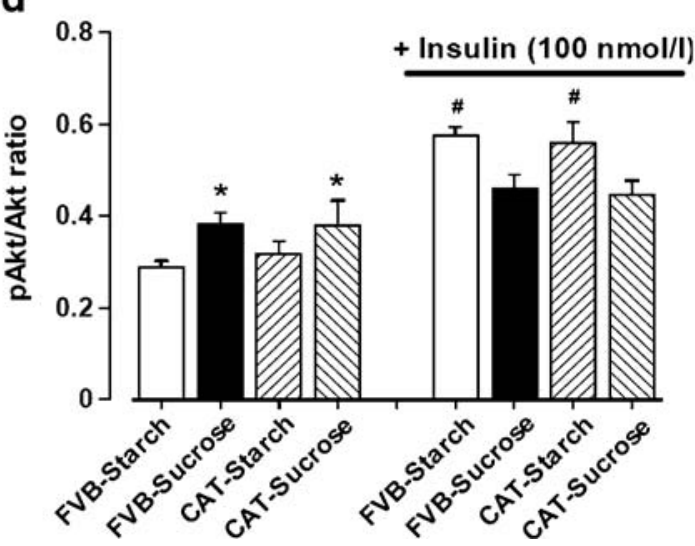

$(p A k t)$ antibodies. b Total Akt expression; c pAkt expression; and d pAkt/Akt ratio. Means \pm SEM, $n=8$ and 4 for non-insulin- and insulin-stimulated groups, respectively, ${ }^{*} p<0.05$ vs FVB-starch group, $\# p<0.05$ vs corresponding non-insulin-stimulated group

catalase rescues insulin-resistance-induced cardiac contractile dysfunction possibly through reduction of ROS generation and protein oxidation as well as restoration of NCX expression, a mechanism independent of insulin signalling.

Insulin resistance impairs cardiac contractile functions in a manner reminiscent of full-blown diabetes [9, 10], suggesting a possible role of prediabetic insulin resistance in diabetic cardiomyopathy. This is supported by the beneficial effects of pharmacological intervention and lifestyle modification including insulin sensitiser, diet restriction and weight loss on insulin sensitivity and cardiac function in patients with type 2 diabetes and obesity $[3,25]$. Our 12-week starch/sucrose dietary feeding did not produce any difference in body or organ weight and fasting blood glucose in either FVB or catalase mice, excluding the potential contribution of obesity and diabetes to the current insulin-resistance experimental model. Data from our present study revealed that ventricular myocytes from sucrose-fed mice exhibited depressed PS amplitude, reduced $\pm \mathrm{dL} / \mathrm{dt}$ and prolonged $\mathrm{TR}_{90}$ associated with normal TPS and HWD. Most of these data are consistent with our previous findings using a similar hyperinsulinaemic insulin-resistance model in rats $[6,26]$. The fact that 
a
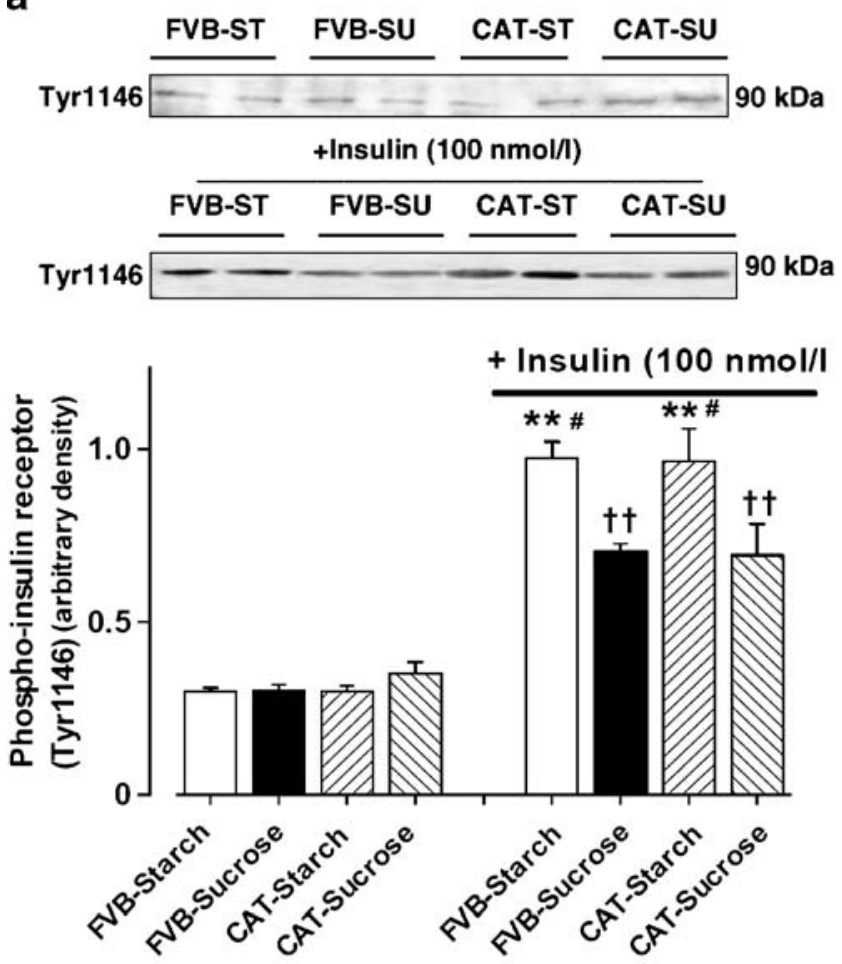

C
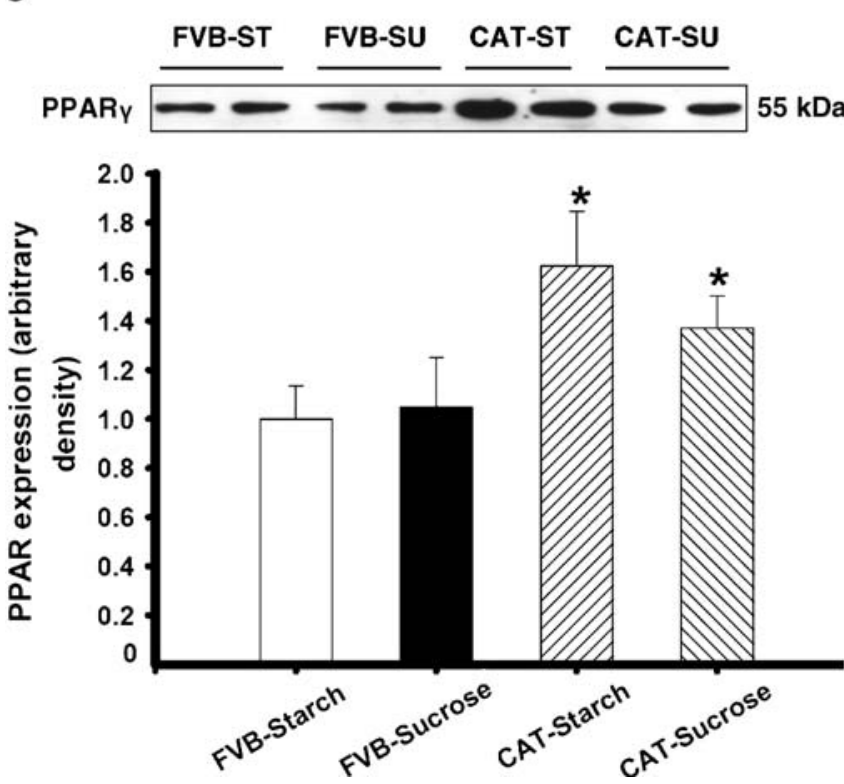

Fig. 10 Western blot analysis showing expression of insulin-receptor phosphorylation (a), PTP1B (b), PPAR $\gamma(\mathbf{c})$ and eNOS (d) in starch$(S T)$ and sucrose $(S U)$-fed FVB and catalase $(C A T)$ mouse hearts. For insulin-receptor phosphorylation (Tyr1146), cardiomyocytes from each of the four groups were treated with or without insulin (100 nmol/1) for $10 \mathrm{~min}$. Insets: Representative immunoblots depicting

our early observation showed either normal $\mathrm{TR}_{90}$ and $\pm \mathrm{dL} / \mathrm{dt}$ or shortened TPS after sucrose-diet feeding may be attributed to relatively short feeding duration (7-10 weeks) [6] and the difference in experimental species (rats vs mice). These mechanical defects are strikingly similar to those reported in ventricular myocytes from full-blown
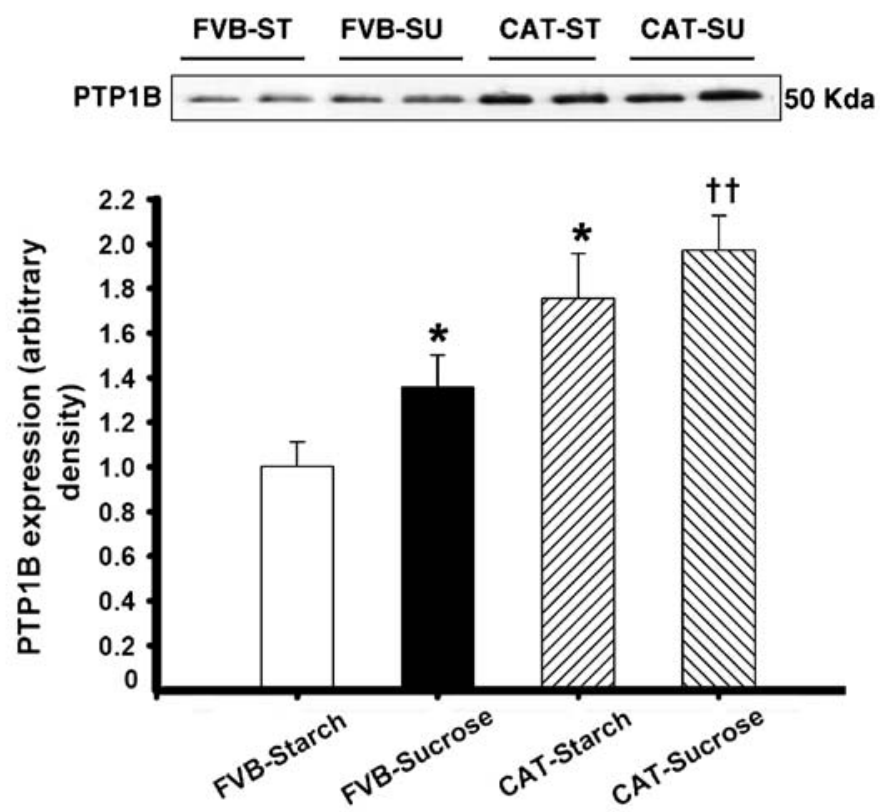

d
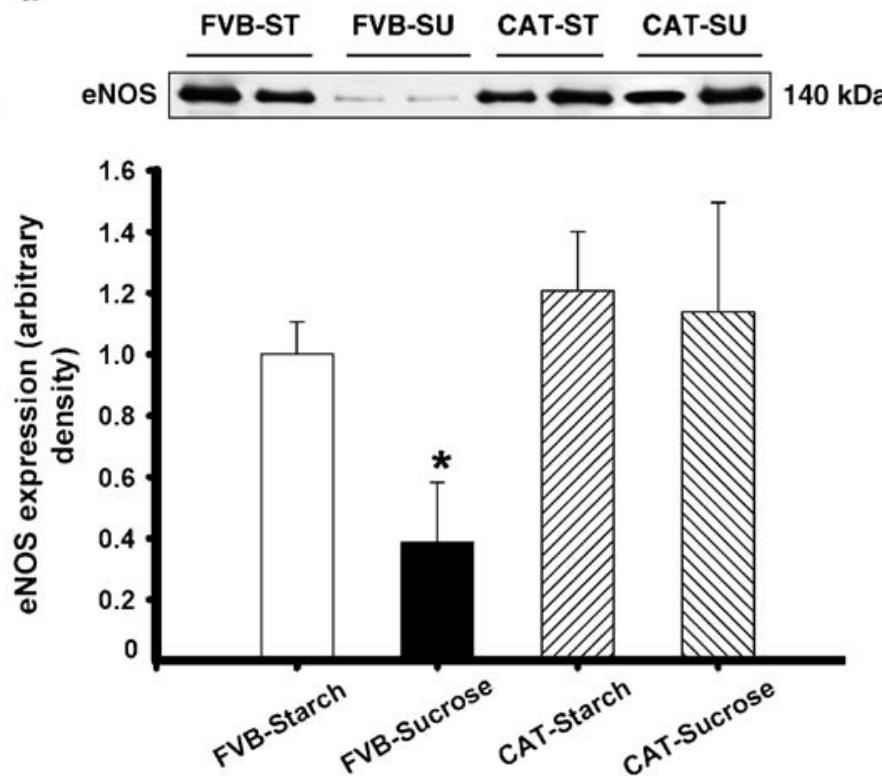

phosphorylation of insulin receptor, PTP1B, PPAR $\gamma$ and eNOS using anti-phospho-insulin receptor (Tyr1146), anti-PTP1B, anti-PPAR $\gamma$ and anti-eNOS antibodies. Means \pm SEM, $n=8$ and 4 for non-insulin and insulin-stimulated groups, respectively, ${ }^{*} p<0.05$ vs FVB-starch group, $\dagger^{*} p<0.05$ vs corresponding non-insulin-stimulated group, $\# p<0.05$ vs FVB-sucrose or corresponding sucrose diet group

diabetes $[9,18,26]$. The increased resting cell length in conjunction with unchanged heart weight or heart:body weight ratio in sucrose-fed mice suggests the possible existence of dilated cardiomyopathy or 'eccentric cardiac hypertrophy' due to volume-overload-induced stretch of ventricles. Insulin resistance is known to be accompanied 
by ventricular pressure or volume overload [2]. The impaired intracellular $\mathrm{Ca}^{2+}$ handling shown as a reduced intracellular $\mathrm{Ca}^{2+}$ clearance rate $(\tau)$ and reduced $\triangle \mathrm{FFI}$ in sucrose-fed FVB mouse myocytes are consistent with those found in diabetic hearts $[9,10,18]$ and are mostly likely responsible for prolonged $\mathrm{TR}_{90}$ and reduced PS amplitude in these cells. The unchanged HWD in conjunction with prolonged relaxation duration and normal contraction duration following sucrose feeding favours the view that impaired relaxation may be due to a defect of the slow phase of relaxation (controlled by NCX and/or the sarcolemmal $\mathrm{Ca}^{2+}$ pump) rather than early relaxation machinery such as myosin heavy chain isozymes and SERCA. This is consistent with our immunoblotting of reduced NCX expression associated with normal SERCA2a and PLB in the sucrose-fed FVB group. The observation that the catalase transgene itself significantly lowered the resting intracellular $\mathrm{Ca}^{2+}$ level may indicate possible protective effects of the antioxidant enzyme against intracellular $\mathrm{Ca}^{2+}$ overload in the heart. $\mathrm{H}_{2} \mathrm{O}_{2}$, the substrate of the catalase enzymatic reaction, is known to lead to accumulation of intracellular $\mathrm{Ca}^{2+}$ and $\mathrm{Ca}^{2+}$ overload in cardiac myocytes [27].

Perhaps the most intriguing finding from our study was that catalase elicits cardiac protection against insulin resistance independently of an improvement in insulin sensitivity. The mechanical and intracellular $\mathrm{Ca}^{2+}$ defects triggered by insulin resistance were alleviated by catalase, in a manner similar to its effect on diabetes-induced cardiac contractile dysfunctions [18]. Cardiomyocyte dysfunction has been demonstrated in animal models of type 2 diabetes or insulin resistance [4-6, 26, 28, 29]. It could be speculated that reduced oxidative stress is responsible for the protection by catalase against insulin-resistance-induced cardiac contractile dysfunction. This is evidenced by the antagonism of catalase against the insulin-resistanceinduced increase in cardiac ROS generation and protein carbonyl formation. Another scenario behind catalaseelicited protection against insulin-resistance-associated cardiomyocyte dysfunction is the antagonism against depressed NCX expression. NCX is an essential cardiac $\mathrm{Ca}^{2+}$-regulating protein responsible for cardiac contractile function, especially the delayed phase of relaxation [30]. SERCA2a and PLB also play major roles in the maintenance of cardiac contractile function, especially the rapid phase of relaxation [31]. Nevertheless, our current finding does not favour any involvement of SERCA2a and PLB in insulin resistance or the catalase-elicited cardiac mechanical effect. Although our study revealed changes of several insulin-signalling molecules in insulin-resistant FVB mice, at both the receptor and post-receptor levels, improvement of cardiac ROS production, protein carbonyl formation and NCX expression in sucrose-fed catalase mice seem to occur independently of these insulin-signalling molecules (tyrosine phosphorylation of insulin receptor, Akt phosphorylation, PTP1B and PPAR $\gamma$ ). This separation between contractile function and insulin signalling was further supported by the inability of catalase transgene to correct insulin-resistance-dampened glucose uptake.
Our data do not favour an involvement of the insulinsignalling cascade in the catalase-elicited protection of cardiomyocyte dysfunction. Nevertheless, several interesting points may be helpful to better understand insulinsignalling mechanisms in cardiomyocytes. Our observation of normal tyrosine phosphorylation of the insulin receptor and enhanced Akt phosphorylation in insulin-resistant mice may indicate a 'pseudo-hyperactivity' of insulin signalling due to a feedback upregulation as a result of desensitised insulin signalling following 12 weeks of sucrose feeding. Either under- or overactivation of the key cardiac survival factor Akt has been demonstrated in various models of type 2 diabetes or insulin resistance [3234], suggesting a crucial role of Akt activation in insulin resistance. It is noteworthy that enhanced Akt phosphorylation may also be attributed to elevated blood insulin levels in sucrose-fed mice. It is not surprising that sucrosefeeding-induced insulin resistance upregulated PTP1B, the negative modulator of insulin signalling [15]. Proteintyrosine phosphatases (PTPs) are extremely sensitive to oxidative stress, which has been suggested as a mechanism for regulation of PTP function [35]. Although oxidative stress may facilitate the tyrosine-phosphorylation-dependent cellular-signalling response of insulin by transiently inactivating the negative-insulin-regulator PTPs, excessive oxidative stress under insulin resistance and diabetes was reported to upregulate the redox-sensitive protein PTP1B [36]. Reduced oxidative stress along with elevated PTP1B expression in sucrose-fed catalase mice again proved the independence of oxidative stress and insulin signalling in our current model of insulin resistance. Furthermore, PPAR $\gamma$ is the adipocyte-predominant transcription factor serving as an insulin sensitiser for glucose and lipid metabolism [14]. Although sucrose-fed insulin resistance failed to alter PPAR $\gamma$ in our current experimental setting, the fact that catalase transgene itself directly enhanced PPAR $\gamma$ levels should assist in correcting the imbalanced redox status triggered by insulin resistance.

Our results indicate that insulin resistance reduced the expression of eNOS, which can be alleviated by the antioxidant catalase. It has been reported previously that reduced eNOS function may underscore cardiac and smooth muscle atherogenesis in fructose-induced insulin resistance and metabolic syndrome [37]. Recent evidence from our laboratory revealed that gene delivery of eNOS into cardiomyocytes directly improved cardiac contractile function through a phosphatidylinositol-3-kinase-dependent mechanism [35]. Additional evidence suggested that impairment of endothelium-dependent vasodilatation is not a direct consequence of reduced activity/expression of eNOS, but is rather triggered by an enhanced inactivation of nitric oxide by oxidative stress, especially ROS [38]. Oxidative stress and impaired cardiac contractile function have been demonstrated in insulin-resistant states such as type 2 diabetes, hypertension and obesity [1, 39]. A highfructose diet has been shown to reduce mRNA expression of antioxidant catalase [40], which itself provides solid support for a therapeutic indication of catalase enzyme. Our present study indicates that the catalase-elicited 
cardiac-protective effect on mechanical function may be related solely to its antioxidant capacity, independently of improved insulin sensitivity. This is somewhat inconsistent with an earlier report that abrogation of oxidative stress improves insulin sensitivity in a Ren2 angiotensin-IIoverexpression rat model [41]. It could be argued that catalase-induced upregulation of PPAR $\gamma$ non-specifically improves cardiac function. Further study is warranted to elucidate the role of PPAR $\gamma$ activation in cardiac contractile function and oxidative stress.

In summary, our present study sheds some light on the interactions between oxidative stress, insulin signalling and insulin-resistance-associated cardiac contractile defects. Given the fact that the precise pathogenesis of cardiac contractile dysfunction, cardiac $\mathrm{Ca}^{2+}$-regulatory protein defect and protein oxidative damage under insulin resistance is far from clear, it is imperative for researchers to delineate the action of insulin-signalling mechanisms under various conditions of oxidative stress in order to better understand the transition from insulin sensitive- to insulinresistant states.

Acknowledgements This work was supported in part by the American Heart Association Northland Affiliate (\#9960204Z) and Pacific Mountain Affiliate (\#0355521Z) and American Diabetes Association (7-0-RA-21) to J. Ren. The catalase founder mice were kindly provided by P. N. Epstein from University of Louisville, Louisville, KY, USA. The anti-PLB antibody was kindly provided by S. Cala, Wayne State University, Detroit, MI, USA. Technical assistance from B. H. Zhao and J. Sotillo was greatly appreciated. Part of this work was presented at the 12th World Congress on Heart Disease in Vancouver, British Columbia, Canada, 16-19 July, 2005.

\section{References}

1. Ceriello A, Motz E (2004) Is oxidative stress the pathogenic mechanism underlying insulin resistance, diabetes, and cardiovascular disease? The common soil hypothesis revisited. Arterioscler Thromb Vasc Biol 24:816-823

2. Reaven GM (1995) Pathophysiology of insulin resistance in human disease. Physiol Rev 75:473-486

3. Wang CC, Goalstone ML, Draznin B (2004) Molecular mechanisms of insulin resistance that impact cardiovascular biology. Diabetes 53:2735-2740

4. Davidoff AJ, Mason MM, Davidson MB et al (2004) Sucroseinduced cardiomyocyte dysfunction is both preventable and reversible with clinically relevant treatments. Am J Physiol Endocrinol Metab 286:E718-E724

5. Dutta K, Podolin DA, Davidson MB, Davidoff AJ (2001) Cardiomyocyte dysfunction in sucrose-fed rats is associated with insulin resistance. Diabetes 50:1186-1192

6. Hintz KK, Aberle NS II, Ren J (2003) Insulin resistance induces hyperleptinemia, cardiac contractile dysfunction but not cardiac leptin resistance in ventricular myocytes. Int J Obes Relat Metab Disord 27:1196-1203

7. Mazumder PK, O’Neill BT, Roberts MW et al (2004) Impaired cardiac efficiency and increased fatty acid oxidation in insulinresistant ob/ob mouse hearts. Diabetes 53:2366-2374

8. Gargiulo P, Jacobellis G, Vaccari V, Andreani D (1998) Diabetic cardiomyopathy: pathophysiological and clinical aspects. Diab Nutr Metab 11:336-346

9. Ren J, Davidoff AJ (1997) Diabetes rapidly induces contractile dysfunctions in isolated ventricular myocytes. Am J Physiol Heart Circ Physiol 272:H148-H158
10. Ren J, Ceylan-Isik AF (2004) Diabetic cardiomyopathy: do women differ from men. Endocrine 25:73-84

11. Cusi K, Maezono K, Osman A et al (2000) Insulin resistance differentially affects the PI 3-kinase- and MAP kinase-mediated signaling in human muscle. J Clin Invest 105:311-320

12. Dorrestijn J, Ouwens DM, Van den Berghe N, Bos JL, Maassen JA (1996) Expression of a dominant-negative Ras mutant does not affect stimulation of glucose uptake and glycogen synthesis by insulin. Diabetologia 39:558-563

13. Hinault C, Mothe-Satney I, Gautier N, Lawrence JC Jr, Van Obberghen E (2004) Amino acids and leucine allow insulin activation of the $\mathrm{PKB} / \mathrm{mTOR}$ pathway in normal adipocytes treated with wortmannin and in adipocytes from $\mathrm{db} / \mathrm{db}$ mice. FASEB J 18:1894-1896

14. Rangwala SM, Lazar MA (2004) Peroxisome proliferatoractivated receptor gamma in diabetes and metabolism. Trends Pharmacol Sci 25:331-336

15. Zabolotny JM, Haj FG, Kim YB et al (2004) Transgenic overexpression of protein-tyrosine phosphatase $1 \mathrm{~B}$ in muscle causes insulin resistance, but overexpression with leukocyte antigen-related phosphatase does not additively impair insulin action. J Biol Chem 279:24844-24851

16. Fisher TL, White MF (2004) Signaling pathways: the benefits of good communication. Curr Biol 14:R1005-R1007

17. Cai L, Kang YJ (2001) Oxidative stress and diabetic cardiomyopathy: a brief review. Cardiovasc Toxicol 1:181-193

18. Ye G, Metreveli NS, Donthi RV et al (2004) Catalase protects cardiomyocyte function in models of type 1 and type 2 diabetes. Diabetes 53:1336-1343

19. Podolin DA, Sutherland E, Iwahashi M, Simon FR, Pagliassotti MJ (1998) A high-sucrose diet alters the lipid composition and fluidity of liver sinusoidal membranes. Horm Metab Res 30:195-199

20. Kang YJ, Chen Y, Epstein PN (1996) Suppression of doxorubicin cardiotoxicity by overexpression of catalase in the heart of transgenic mice. J Biol Chem 271:12610-12616

21. Zhang X, Klein AL, Alberle NS et al (2003) Cardiac-specific overexpression of catalase rescues ventricular myocytes from ethanol-induced cardiac contractile defect. J Mol Cell Cardiol 35:645-652

22. Hintz KK, Relling DP, Saari JT et al (2003) Cardiac overexpression of alcohol dehydrogenase exacerbates cardiac contractile dysfunction, lipid peroxidation, and protein damage after chronic ethanol ingestion. Alcohol Clin Exp Res 27:1090-1098

23. Dong F, Zhang X, Wold LE, Ren Q, Zhang Z, Ren J (2005) Endothelin-1 enhances oxidative stress, cell proliferation and reduces apoptosis in human umbilical vein endothelial cells: role of ETB receptor, NADPH oxidase and caveolin-1. Br J Pharmacol 145:323-333

24. Davidoff AJ, Davidson MB, Carmody MW, Davis ME, Ren J (2004) Diabetic cardiomyocyte dysfunction coupled to myocyte insulin resistance: role of glucose-induced PKC activity. Mol Cell Biochem 262:155-163

25. Matthaei S, Stumvoll M, Kellerer M, Haring HU (2000) Pathophysiology and pharmacological treatment of insulin resistance. Endocr Rev 21:585-618

26. Ren J, Sowers JR, Walsh MF, Brown RA (2000) Reduced contractile response to insulin and insulin-like growth factor I in ventricular myocytes from genetically obese Zucker rats. Am J Physiol Heart Circ Physiol 279:H1708-H1714

27. Sharikabad MN, Ostbye KM, Brors O (2004) Effect of hydrogen peroxide on reoxygenation-induced $\mathrm{Ca}^{2+}$ accumulation in rat cardiomyocytes. Free Radic Biol Med 37:531-538

28. Schaffer SW, Ballard-Croft C, Boerth S, Allo SN (1997) Mechanisms underlying depressed $\mathrm{Na}^{+} / \mathrm{Ca}^{2+}$ exchanger activity in the diabetic heart. Cardiovasc Res 34:129-136

29. Shimoni Y, Ewart HS, Severson D (1998) Type I and II models of diabetes produce different modifications of $\mathrm{K}^{+}$currents in rat heart: role of insulin. J Physiol 507:485-496

30. Goldhaber JI, Henderson SA, Reuter H, Pott C, Philipson KD (2005) Effects of $\mathrm{Na}^{+}-\mathrm{Ca}^{2+}$ exchange expression on excitationcontraction coupling in genetically modified mice. Ann NY Acad Sci 1047:122-126 
31. Bers DM (2002) Cardiac excitation-contraction coupling. Nature 415:198-205

32. Ren J, Duan J, Hintz KK, Ren BH (2003) High glucose induces cardiac insulin-like growth factor I resistance in ventricular myocytes: role of Akt and ERK activation. Cardiovasc Res 57:738-748

33. Huisamen B (2003) Protein kinase B in the diabetic heart. Mol Cell Biochem 249:31-38

34. Tomas E, Lin YS, Dagher Z et al (2002) Hyperglycemia and insulin resistance: possible mechanisms. Ann NY Acad Sci 967:43-51

35. Ren J, Zhang X, Scott GI et al (2004) Adenovirus gene transfer of recombinant eNOS enhances contractile function in ventricular myocyte. J Cardiovasc Pharm 43:171-177

36. Meng TC, Buckley DA, Galic S, Tiganis T, Tonks NK (2004) Regulation of insulin signaling through reversible oxidation of the protein-tyrosine phosphatases TC45 and PTP1B. J Biol Chem 279:37716-37725
37. Miatello R, Risler N, Castro C, Gonzalez S, Ruttler M, Cruzado M (2001) Aortic smooth muscle cell proliferation and endothelial nitric oxide synthase activity in fructose-fed rats. Am J Hypertens 14:1135-1141

38. Stockklauser-Farber K, Ballhausen T, Laufer A, Rosen P (2000) Influence of diabetes on cardiac nitric oxide synthase expression and activity. Biochim Biophys Acta 1535:10-20

39. Penckofer S, Schwertz D, Florczak K (2002) Oxidative stress and cardiovascular disease in type 2 diabetes: the role of antioxidants and pro-oxidants. J Cardiovasc Nurs 16:68-85

40. Cavarape A, Feletto F, Mercuri F, Quagliaro L, Daman G, Ceriello A (2001) High-fructose diet decreases catalase mRNA levels in rat tissues. J Endocrinol Invest 24:838-845

41. Blendea MC, Jacobs D, Stump CS et al (2005) Abrogation of oxidative stress improves insulin sensitivity in the Ren2 rat model of tissue angiotensin II overexpression. Am J Physiol Endocrinol Metab 288:E353-E359 